\title{
Tube Migration Leading to Gastric Outlet Obstruction: An Unusual Complication of Percutaneous Endoscopic Gastrostomy
}

\author{
Cameron Caners ${ }^{\mathrm{a}}$, Abhishek Bhurwal ${ }^{\mathrm{a}, \mathrm{b}}$, David Rahni ${ }^{\mathrm{a}}$
}

\begin{abstract}
Percutaneous endoscopic gastrostomy (PEG) placement is a wellestablished technique for administering long-term enteral nutrition. Gastric outlet obstruction is a rare complication of gastrostomy tube placement caused by migration of the tube into pyloric channel or duodenal bulb. A 72-year-old female presented with complaints of nausea and abdominal pain after recent PEG placement. The diagnosis of tube migration leading to gastric outlet obstruction was made after the inflated Mickey balloon was visualized obstructing the pyloric channel. The Mickey tube was carefully extracted with an endosnare. Early recognition of the tube migration leading to obstructive symptoms in a clinically appropriate scenario prevents further complications such as ulceration, necrosis and avoids surgical intervention.
\end{abstract}

Keywords: PEG tube; Gastric outlet obstruction; Complication

\section{Introduction}

Percutaneous endoscopic gastrostomy (PEG) has been an extensively employed technique for establishing a feeding gastrostomy since 1980 [1]. It is favored because the procedure is performed quickly and easily. PEG is generally associated with infrequent mortality and morbidity as compared to conventional operative gastrostomy [1]. We present a rare case of internal gastrostomy tube migration leading to gastric outlet obstruction which was successfully managed endoscopically.

\section{Case Report}

A 72-year-old female with past medical history of congenital

\footnotetext{
Manuscript submitted October 25, 2017, accepted November 3, 2017

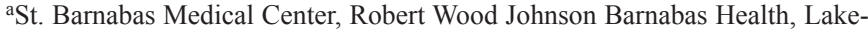
wood, NJ, USA

bCorresponding Author: Abhishek Bhurwal, St. Barnabas Medical Center, Robert Wood Johnson Barnabas Health, Lakewood, NJ, USA.

Email: abhishek.bhurwal@gmail.com
}

ataxia and intellectual disability with persistent oropharyngeal dysphagia and PEG placement for nutritional support for the last two decades presented to the emergency room with complaints of a misplaced feeding tube. Over the last 3 weeks, the patient would get agitated and would pull the PEG tube out which led to multiple bedside and/or endoscopic PEG replacements. Thereafter, the 28 Fr PEG tube was changed to a Mickey. It is shorter in length, and thus less prone to dislodgement. Specifically, a 24 Fr Mickey was selected as it is the largest diameter Mickey available.

After 28 days of Mickey placement without any issues, the patient presented again to our emergency room with misplaced Mickey tube. On physical examination, the extension tubing was observed coming out of the gastro-cutaneous fistula tract. The diagnosis of internal tube migration into the stomach was considered as the Mickey tube along with the external bumper was not visualized. The abdominal X-ray performed revealed that the contrast filled Mickey balloon was noticed in the stomach (Fig. 1). At bedside, an attempt was made to pull the Mickey through the formed fistula tract, but the effort was unsuccessful. Thus, a decision was made to undergo a concomitant esophagogastroduodenoscopy (EGD), which revealed that the Mickey tube had migrated entirely into the stomach with the inflated Mickey balloon obstructing the pylorus (Fig. 2). The balloon was then successfully deflated with an endoscopic

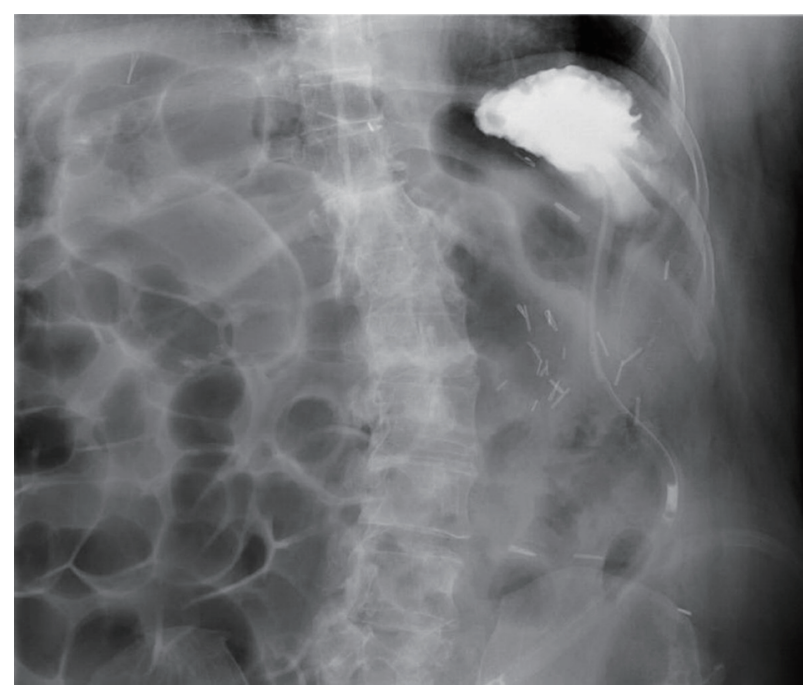

Figure 1. Contrast filled balloon in the stomach. 


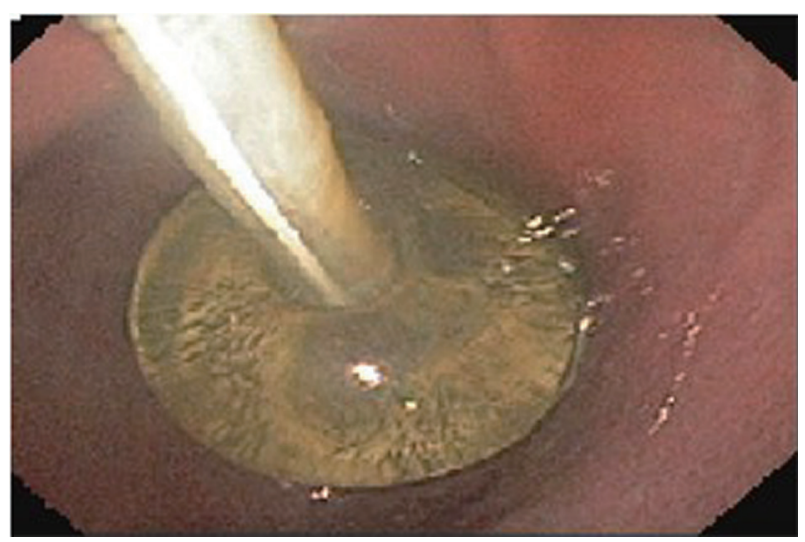

Figure 2. Balloon obstructing the pyloric channel.

injection needle (Fig. 3). The extension tubing on the external surface of the body was then cut, and the Mickey tube was removed completely with the use of an endosnare without any complications through the oral cavity. Subsequently, a new 28 Fr PEG tube was placed and secured in appropriate fashion.

\section{Discussion}

PEG placement is a well-established technique for administering long-term enteral nutrition. Gastric outlet obstruction is a rare complication of gastrostomy tube placement caused by migration of the tube into pyloric channel or duodenal bulb [2-5].

Internal tube migration presents with obstructive symptoms of nausea, vomiting and crampy abdominal pain [4]. The absence of external bolster (such as in Foley Catheter) and placement of gastrostomy tube in pylorus are risk factors leading to gastric outlet obstruction. An abdominal X-ray or endoscopy usually confirms the diagnosis. It is extremely important to recognize the possibility of tube migration in appropriate clinical settings as delay in recognition may lead to necrosis or ulceration of the tissue. Careful retraction of the tube through the fistula tract, or endoscopic extraction, would

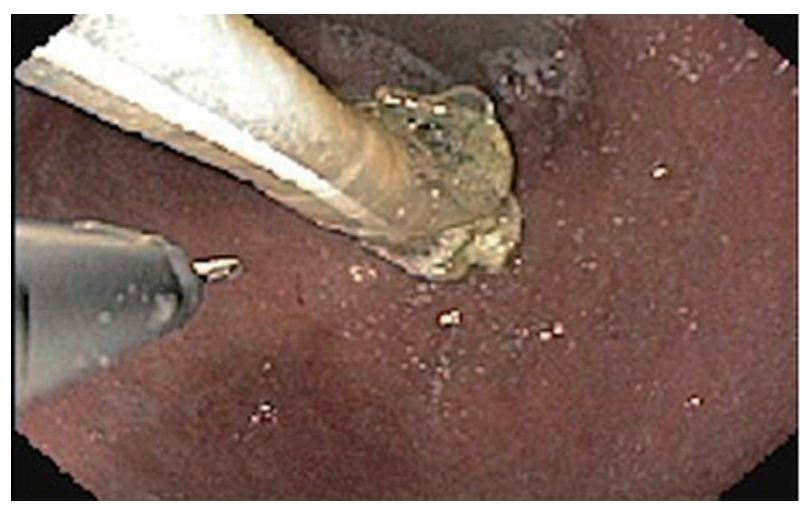

Figure 3. Deflated balloon prior to removal.

solve the problem in majority of the cases.

In summary, if a patient with ballooned feeding tube develops obstructive intestinal symptoms, internal migration should be considered. Early recognition aids in prevention of morbidity in terms of small bowel obstruction, ulceration and avoids surgical intervention.

\section{References}

1. Ponsky JL, Gauderer MW. Percutaneous endoscopic gastrostomy: a nonoperative technique for feeding gastrostomy. Gastrointest Endosc. 1981;27(1):9-11.

2. McGovern R, Barkin JS, Goldberg RI, Phillips RS. Duodenal obstruction: a complication of percutaneous endoscopic gastrostomy tube migration. Am J Gastroenterol. 1990;85(8):1037-1038.

3. Date RS, Das N, Bateson PG. Unusual complications of ballooned feeding tubes. Ir Med J. 2002;95(6):181-182.

4. Fischer LS, Bonello JC, Greenberg E. Gastrostomy tube migration and gastric outlet obstruction following percutaneous endoscopic gastrostomy. Gastrointest Endosc. 1987;33(5):381-382.

5. Chong VH. Gastric outlet obstruction caused by gastrostomy tube balloon. Indian J Gastroenterol. 2004;23(2):80. 